\title{
REUTILIZAÇÃO DO ESGOTO DOMÉSTICO NA AGRICULTURA COMO FONTE DE NUTRIENTES PARA AS PLANTAÇÕES
}

SANTIAGO, M. S. (IFRN)*; OLIVEIRA, K. P. (IFRN)

\section{RESUMO}

A Região do semiárido Nordestino é uma das regiões que mais sofre quanto ao acesso ao saneamento básico, mas novas pesquisas vêm sendo desenvolvidas com intuito de amenizar a escassez de água que vem assolando estas regiões. Diante disso, o presente artigo teve como objetivo abordar o potencial e as principais dificuldades enfrentadas na utilização do esgoto tratado na agricultura. Assim percebe-se que a reutilização do esgoto tratado é uma ótima alternativa tanto para agricultura em regiões semiáridas, como em outros serviços que necessitem de água e ao mesmo tempo fornecem nutrientes de boa qualidade para o fortalecimento da planta e do solo

PALAVRAS-CHAVE: esgoto, reutilização, agricultura.

\section{REUSE OF SEWAGE HOME IN AGRICULTURE AS A SOURCE OF NUTRIENTS FOR THE PLANTATION}

\section{ABSTRACT}

The Northeastern semi-arid region is one of the regions most affected in terms of access to basic sanitation, but new research is being developed in order to alleviate the shortage of water coming plaguing these regions. Therefore, this article aims to address the potential and the main difficulties in the use of treated wastewater in agriculture. So we realize that the reuse of treated sewage is a great alternative for both agriculture in semi-arid regions, as in other services that require water and at the same time provide good quality nutrients to strengthen the plant and soil.

KEY-WORDS: Sewer, reuse, agriculture. 


\section{REUTILIZAÇÃO DO ESGOTO DOMÉSTICO NA AGRICULTURA COMO FONTE DE NUTRIENTES PARA AS PLANTAÇÕES}

\section{INTRODUÇÃO}

O Nordeste é a região brasileira que possui a maior quantidade de estados e é divido por quatro sub-regiões: meio-norte, zona da mata, agreste e sertão. Dentre as subregiões que mais sofrem economicamente, socialmente e ambiental é o sertão, extensa área de clima semiárido, pois tem características que afetam diretamente e indiretamente a população daquela região como: aridez climática, deficiência hídrica, imprevisibilidade das precipitações pluviométricas e presença de solo pobre em matéria orgânica. Entre as características mais marcantes dessa região, destaca-se a aridez sazonal que consistem em longo período seco anual, pelo motivo, da elevada temperaturas dessa região (MALAQUIAS, 2010).

Diante deste contexto, percebe-se a importância da ciência e da tecnologia como ferramenta com o intuito de superar as dificuldades vivenciadas nessa região, que necessita de água para a sobrevivência da população e dos animais, como também, para o desenvolvimento das atividades econômicas. Dessa forma, novas tecnologias de tratamento de esgoto seguro e sem representar riscos de transmissão de poluentes, estão sendo desenvolvidas para o reuso do esgoto tratado nessas regiões com o propósito de amenizar as dificuldades encontradas na agricultura, dentre elas, podemos citar baixa qualidade da água e pouca fertilidade do solo.

0 reuso de esgoto tratado na agricultura apresenta destaque, mas para ser utilizado deve, prioritariamente, ser feito um bom planejamento e gestão desse tratamento, pois existe componentes benéficos como fonte de nutrientes, água para a agricultura e ao mesmo tempo componentes prejudiciais que podem causar danos ao solo e corpos d'agua (WHO, 2006). Estudos realizados em regiões semiáridas em Israel revelam que as águas residuais que são submetidas a tratamentos adequados, a fim de, cumprir com as exigências ambientais e sanitárias daquela localidade trazem grandes benefícios a saúde da população e ao setor agrícola naquela região (FRIEDLER,2011).

Entretanto, no Brasil, ainda não existe legislação nem critérios próprios para reuso de água de esgoto tratado, pois ainda faltam estudos sobre os melhores parâmetros de segurança que devem ser aplicados para cada tipo de cultura. Como também, se precisa conhecer quais os principais danos que cada contaminante pode ocasionar ao sistema solo-água-planta, como também, faltam tratamento e investimento público que em muitas vezes é dificultado, por se tratar de um investimento de alto custo (BERTONCINI, 2008).

Apesar da inexistência dessas normas de utilização de esgotos domésticos na agricultura brasileira, percebe-se nos dias de hoje um crescimento na utilização desses reuso em todos os continentes, mas para prevenir contra contaminantes de efluentes no setor agrícola do Brasil a Organização Mundial da Saúde (OMS, 2006) que trata, especificamente, de irrigação irrestrita, recomenda que os parâmetros microbiológicos, permitidos de coliformes fecais e ovos de helmintos tenham densidades de 103 a 106 de Escherichia coli em 100 mililitros de efluente, e iguais ou inferiores a 1,0 (um) ovo de helminto por litro de efluente, seja implementado, dependendo do tipo de cultura a ser irrigada com o intuito de controlar seu uso.

Diante disso, o presente artigo tem como objetivo abordar o potencial e as 
principais dificuldades enfrentadas na utilização do esgoto tratado na agricultura, na região do Nordeste Brasileiro, o qual será abordado um levantamento da atual situação do saneamento nessa região, como também, os potencias e desafios encontrados na aplicação dessa metodologia, no semiárido brasileiro.

\section{SANEAMENTO NO BRASIL}

O Brasil ainda vive com grandes desigualdades no que diz respeito ao saneamento básico, pois a grande maioria da população, principalmente, aquelas de baixa renda não tem acesso digno a nenhum serviço de saneamento. E atrelado a toda esta situação ouve um aumento significativo da população que vive na área urbana em meados da década de 40 impulsionados pela industrialização. Observa-se nessa época que a preocupação do saneamento básico recaiu mais fortemente na distribuição de água que era uma demanda mas solicitada pela sociedade do que o esgotamento sanitário.

Diante deste contexto, a situação ainda se agrava pela falta de investimentos e sensibilização por parte da administração pública deixando a população sem alternativas, a não ser jogar os rejeitos sem nem um tratamento ambientalmente adequado nas ruas, córregos, sistemas de drenagens e etc. Dessa forma, aumentando sem nenhum controle o volume de esgoto.

Em 2010 o governo implementa o Plano Nacional de Saneamento tentando consolidar a universalização dos serviços de saneamentos. Mas, o cenário de algumas regiões do país ainda passam por dificuldades quanto ao saneamento, pois na tabela 1 pode-se verificar que a distribuição do saneamento segue um rendimento mensal de cada região. Em média o Brasil tem um valor de rendimento de $\mathrm{R} \$ 668,00$, e em termos de esgotos adequado o Brasil está na casa dos $61,8 \%$, semi-adequado $30,1 \%$ e inadequado $8,1 \%$. O pais mesmo em desenvolvimento ainda temos locais sem saneamento adequado.

Tabela 1 - Proporção de domicílios com saneamento adequado, semi-adequado e inadequado distribuídos no Brasil

\begin{tabular}{l|c|c|c|c}
\hline \multirow{2}{*}{ Região } & \multicolumn{2}{c|}{$\begin{array}{c}\text { Rendimento } \\
\text { Mensal }\end{array}$} & \multicolumn{3}{|c}{$\begin{array}{c}\text { Distribuição percentual, por tipo de } \\
\text { saneamento (\%) }\end{array}$} \\
\cline { 3 - 5 } & Valor Médio (R\$)* & Adequado & Semi-adequado & Inadequado \\
\cline { 3 - 5 } & 668 & 61,8 & 30,1 & 8,1 \\
\hline Brasil & 444 & 22,4 & 58,0 & 19,6 \\
\hline Norte & 407 & 40,0 & 45,0 & 15,0 \\
\hline Sudeste & 812 & 82,3 & 14,5 & 3,3 \\
\hline Sul & 794 & 64,9 & 30,0 & 5,1 \\
\hline Centro-Oeste & 808 & 47,2 & 45,0 & 7,9 \\
\hline Rio Grande do & 475 & 42,0 & 50,1 & 7,9 \\
Norte & & & & \\
\hline
\end{tabular}




\begin{tabular}{l|c|c|c|c}
\hline Natal & 803 & 61,8 & 38,0 & 0,2 \\
\hline Mossoró & 536 & 61,4 & 34,8 & 3,8 \\
\hline Parnamirim & 742 & 55,1 & 44,7 & 0,2 \\
\hline
\end{tabular}

*Rendimento mensal total domiciliar per capita nominal.

Fonte: IBGE, Censo Demográfico 2010.

Verificando as regiões o Sudeste é o que mais tem um rendimento mensal, consecutivamente, a distribuição de saneamento é a melhor do país, com $82,3 \%$ de saneamento adequado e 3,3\% inadequado. O Nordeste está na quarta posição, tanto no rendimento mensal, quanto na distribuição de saneamento. Tendo como adequado $40 \%$ e inadequado $15 \%$, a frente da região sudeste, o Nordeste ainda precisa melhorar muito no saneamento básico das cidades.

Uma coisa que pode se verificar na tabela é que quanto maior é o rendimento mensal da região, mais adequados são os saneamentos nas mesmas.

Na tabela 2 mostra o índice da coleta de esgoto e do tratamento do mesmo no Nordeste. Verifica-se que só o Ceará e Sergipe têm $100 \%$ do seu esgoto tratado e no Maranhão não chega nem a $50 \%$. Ao todo o Nordeste tem $89,16 \%$ do seu esgoto tratado, isto está relacionado as políticas públicas de cada estado e requer maior atenção por parte do governo em geral.

Tabela 2 - Índices de coleta e tratamento de esgoto na região nordeste do Brasil.

\begin{tabular}{c|c|c}
\hline Estado & $\begin{array}{c}\text { IN015 - Índice de coleta } \\
\text { de esgoto (percentual) }\end{array}$ & $\begin{array}{c}\text { IN016 - Índice de tratamento } \\
\text { de esgoto (percentual) }\end{array}$ \\
\hline RN & 23,94 & 83,52 \\
\hline AL & 21,14 & 95,64 \\
\hline BA & 51,39 & 98,45 \\
\hline MA & 35,66 & 100,0 \\
\hline PB & 27,85 & 21,77 \\
\hline PE & 35,96 & 97,81 \\
\hline PI & 26,75 & 98,95 \\
\hline SE & 08,35 & 100,0 \\
\hline Nordeste Total & 22,99 & 89,16 \\
\hline
\end{tabular}

Fonte: SNIS, 2013.

\section{APLICABILIDADE DE ESGOTO}

4a Semana de Química - IFRN, 2016 


\subsection{REUSO DE ÁGUA DE ESGOTO}

O hoje em dia o que podemos perceber é um crescimento constante da população e aliado a isso, o uso exagerado da demanda por água, tanto para consumo direto como para a utilização em processos produtivos. Logo, percebe-se uma demanda na geração de esgotos proveniente desses usos. Diante disso, vem surgindo a preocupação cada vez mais sobre o que fazer com este efluente para não ser descartado de forma errada nos corpos d'aguas ou na superfícies do solo e assim prejudicar o meio ambiente.

O tratamento do esgoto é uma das maneiras mais eficaz para se fazer o reuso do efluente, pois consiste em capitar o esgoto por tanques, ao qual é submetido a uma serie de etapas que incluem floculação, separação de impurezas, filtragens, cloração até que a água poluída esteja apta a ser reutilizada ou devolvida sem ser uma ameaça à saúde e ao meio em que vivemos.

Dessa forma, água do reuso de esgoto quando tratada com eficiência pode ser utilizada em vários aspectos, dentre eles podemos citar: Utilização em shoppings, irrigação de jardins, lavagens de calçadas e pistas, em edificações, alimentação de animais, hidropônica, na irrigação de parques públicos, centros recreativos, campos esportivos, torres de resfriamentos, na agricultura, piscicultura e obras civis, etc.

Contudo, estudos realizados pelo PROSAB em Estações de Tratamento de Esgotos em várias regiões de Brasil com fins de reuso de esgoto tratado na cultura de irrigação, constata-se que apesar de ter boa viabilidade e eficiências na aplicação do efluente, ainda não tem uma ampla utilização e se resume apenas a pequenas instalações, ao qual se pode dizer que é ocasionado por ainda não ter uma regulamentação em nosso país para esta prática. Dessa forma, com o propósito de regulamentar o reuso do esgoto os pesquisadores do Prosab buscaram uma forma de regulamentar esta pratica confrontando as pesquisas e as legislações internacionais afim de encontrar padrões de qualidade da água residual para que pudessem ser utilizadas na irrigação de culturas. Contudo pode-se dizer que a grande maioria dos pesquisadores desse estudo revela que a irrigação de culturas por esgoto tratado e uma pratica viável e recomendável, capaz de atender aos critérios agronômicos, sanitários e ambientais dando uma total segurança a população atual, sem comprometimento das necessidades das gerações futuras (PROSAB, 2009).

Diante desse contexto, Pesquisas desenvolvidas na UFC com a utilização de esgoto tratado em lagoas de estabilização no cultivo de tilápia do Nilo sem ração, constatou-se que após várias análises as tilápias tiveram um bom rendimento em termos de parâmetros zootécnicos e taxa de sobrevivências, ou seja, os resultados são satisfatório para o cultivo dessa espécies com reuso do esgoto tratado, pois trousse os nutrientes necessários para o desenvolvimentos das tilápias sem a necessidade de ração (PROSAB, 2009).

Já em relação a agricultura o reuso da água de esgoto tratado também é uma forma muito boa, pois a água é rica em nutrientes como fosforo e nitrogênio. Além disso o reuso do esgoto tratado na agricultura melhora os problemas de poluição de águas superficiais, o que não só permite a conservação das fontes naturais, mas também o bom desenvolvimento de plantas cultivadas. Os nutrientes que acompanham a utilização dessas águas ajuda na diminuição dos fertilizantes comerciais, sendo assim o agricultor terá menos custos no cultivo da sua plantação. Isso ajuda o desenvolvimento agrícola em 
regiões que tem uma capacidade muito pouca ou nem um dos recursos hídricos como o Nordeste.

O esgoto tratado uma vez no solo provocam rápidas mudanças nos parâmetros físicos, pois os resíduos orgânicos adicionais tendem a diminuir a densidade do solo e assim aumentando a agregação de partículas e melhorando as condições de aeração do solo. As melhorias químicas do solo também são aguardadas, por conta da adição, via esgoto, de nutrientes mineralizados (MARQUES, 2003).

\subsection{BENEFÍCIOS DA UTILIZAÇÃO DO ESGOTO TRATADO NA ECONOMIA, E NA SAÚDE PÚBLICA}

Economicamente os benefícios são ótimos, principalmente para áreas que necessitam da irrigação natural proveniente das chuvas, como o nordeste. Alguns estudos em outros países mostram que a produção agrícola cresce bastante com sistemas de irrigação com esgotos adequadamente administrados, e quando o clima favorece, é possível efetuar várias colheitas durante todo o ano.

Na saúde pública, o reuso do esgoto ajuda a minimizar as descargas dos esgotos nos corpos d'água. Com isso à uma redução de doenças veiculadas a fontes hídrica provocadas por patógenos e substâncias químicas presentes nestes efluentes. Uma vez integrado ao sistema de coleta, tratamento e reuso agrícola, permite a otimização em termos de transporte do efluente e disposição (PESCOD, 1992).

Além disso o reuso do esgoto na irrigação de plantações contribui e muito para as áreas carentes como o agreste nordestino e com isso ajuda o aumento da produção de alimentos e elevando assim a saúde e a qualidade devida da população.

\subsection{USO DE LODO DE ESGOTO NA AGRICULTURA}

O uso do lodo de esgoto pode ser utilizado para a produção de tapetes de grama, pois aumenta significativamente a eficiência da adubação nitrogenada para o gramado. 0 composto de lodo de esgoto, que, em razão das suas características, pode ser uma fonte para substitui partes ou o total da adubação inorgânica para as mesmas. A utilização de lodo na produção de grama proporciona um adequado fornecimento de nutrientes, isso quando aplicado superficialmente, em doses maiores que $36 \mathrm{mg} / \mathrm{ha}-1$. A utilização do lodo na produção de gramas traz benefícios para o solo, tanto na diminuição de $\mathrm{pH}$ quanto na produção de nutrientes orgânicos e inorgânicos (BACKES, 2013).

Outra utilização do esgoto na agricultura em geral (pinhão manso por exemplo). A utilização do lodo de esgoto na agricultura como adubo orgânico, é hoje uma alternativa muito promissora para a destinação final do resíduo em razão da sua sustentabilidade. A utilização do biossólido nas sementes de pinhão manso foram promissores quando utilizado $10 \%$ do mesmo, as mudas apresentaram um ótimo crescimento (CAMARGO, 2010).

Além de pinhão manso, o biossólido também é utilizado no crescimento de mudas de aroeiras. A utilização do biossólido melhorou a fertilização dos substratos, o aumento dos nutrientes orgânicos e inorgânicos, o aumento da matéria orgânica e os teores de micronutrientes, gerando assim uma muda de proporção de 63:37. Nesse trabalho foi utilizado tanto os compostos de amostras de Neossolo Quartzarênico e de Latossolo Vermelho-Amarelo coletadas na profundidade de 0,2 a 0,5 m, acrescidos do biossólido produzido pela Estação de Tratamento de Esgoto (ETE) de Serrania, MG (NÓBREGA, 2007). 
Outra alternativa da utilização do lodo de esgoto proveniente do tratamento, é como substratos na produção de mudas de Chamaecrista desvauxii. A utilização do lodo proporcionou um ótimo resultado nas características avaliadas morfologicamente, além da utilização de outros materiais como forma de avaliar a capacidade na produção das mudas. O trabalho utilizou além do substrato do lodo, a casca de arroz carbonizada, palha de café in natura e substrato comercial, em diferentes proporções de volume. E como resultado tivemos o substrato do lodo com $60 \%$ na adequação de suas características na produção das mudas (CALDEIRA, 2013).

Verifica-se que o substrato de lodo proveniente do tratamento de esgotos nas ETEs, tem bastante aplicabilidade na agricultura, com um alto índice de nutrientes orgânicos e inorgânicos, que ajuda no crescimento das mudas. O material também é rico em matéria orgânica, sais minerais e que é sempre bom para a produção agrícola e também de mudas florestais.

\subsection{RISCOS ASSOCIADOS AO USO DE ESGOTO}

Muitos riscos estão associados ao reuso do esgoto, um dos riscos são a quantidade de metais pesados que estão acoplados ao esgoto, estes metais tem um índice muito alto de toxicidade e que é prejudicial ao homem. Os tipos de metais pesados provenientes do esgoto são bem variados, mas os que são mais encontrados é o $\mathrm{Cd}, \mathrm{Cr}, \mathrm{Ni}, \mathrm{Pb}, \mathrm{Zn}$, dentre outros.

\begin{tabular}{l|l}
\multicolumn{2}{c}{ Tabela 3 - Doenças causadas por metais pesados } \\
\hline $\begin{array}{l}\text { Metais } \\
\text { pesados }\end{array}$ & Tipos de doenças \\
\hline Cadmio (Cd) & Causa problemas gastrointestinais e respiratórios. \\
\hline Crómio (Cr) & Provoca irritação na pele e, em doses elevadas, câncer. \\
\hline Níquel (Ni) & É a dermatite de contato alérgica. \\
\hline Chumbo $(\mathrm{Pb})$ & Atinge o sistema nervoso, a medula óssea e os rins. \\
\hline Zinco $(\mathrm{Zn})$ & $\begin{array}{l}\text { Pode produzir um sabor metálico, vómitos e problemas no } \\
\text { estômago. }\end{array}$ \\
\hline
\end{tabular}

Fonte: Mundo Educação

Além dos metais pesados ainda a o risco biológico da reutilização dos esgotos, pois a presenças de muitos microrganismos patogênicos, tais como vírus, protozoários e helmintos. Muitos destes patógenos estão presentes em altas concentrações, e podem sobreviver até por meses nos esgotos, em solos ou em áreas cultivadas pelo mesmo. Isso oferece um grande risco a população que consome as plantas que estão sendo cultivadas pelo reuso do esgoto, os agricultores e as pessoas que os manipulam.

Vale salientar que a presença dos organismos patogênicos no esgoto, solo ou na cultivação, não significa a transmissão de doenças. Isso se deve as barreiras protetoras naturais providenciadas pelos fatores dos microrganismos (dose efetiva, carga residual, etc), dos hospedeiros (imunidade natural, condições gerais de saúde) e outros fatores que possibilitam a diminuição do risco de adquirir doenças por organismos patogênicos (HESPANHOL, 2002).

4a Semana de Química - IFRN, 2016 
Tabela 4 - Risco associado ao reuso de esgoto doméstico

\begin{tabular}{l|l}
\hline Risco & Organismo \\
\hline Alto risco & $\begin{array}{l}\text { Helmintos, nematóides intestinais } \\
\text { humanos (A. lumbricoides, Trichuris } \\
\text { trichiura, N. americanus e A.duodenale). }\end{array}$ \\
\hline Médio risco & $\begin{array}{l}\text { Bactérias (V. chlolerae, S. tyhi e Shigellae } \\
\text { ssp.) e protozoário (E. hystolitica, Giárdia } \\
\text { sp. e Cryptosporidium ssp.). }\end{array}$ \\
\hline Baixo risco & Vírus (enterovírus e vírus da hepatite) \\
\hline
\end{tabular}

Fonte: Adaptado de Shuval (1986)

Além dos riscos citados a cima, também existe os riscos da salinização, já que existem sais e sólidos dissolvidos nos efluentes e que acabam acarretando diretamente a nutrição do vegetal. Embora exista muitas culturas que são tolerantes a salinização, são necessários um grande monitoramento e uma administração da irrigação e sua sustentabilidade em todo o sistema. Os excessos de sais no corpo hídrico utilizado para a irrigação de plantações podem ter elevadas concentrações de íons que podem tornar-se tóxicos e acarretar na interferência da absorção de nutrientes por parte das plantas.

\section{CONCLUSÃO}

Diante das revisões literárias feitas pelo artigo percebe-se que ainda algumas regiões, principalmente, Norte e Nordeste do Brasil ainda vive com dificuldades quanto ao acesso a um saneamento básico de qualidade, mas podemos detectar também que com o passar do tempo novas políticas públicas vem surgindo no intuito de universalizar o saneamento básico. Contudo, as pesquisas evidenciaram também que o uso de esgoto tratado sendo bem planejado e gerenciado podem ser um excelente efluente para ser utilizado em regiões com escassez de água, visto que, as análises permitiram constatar bons resultados na agricultura e piscicultura. Por fim, ainda percebemos que o Brasil ainda precisa de uma legislação mais atualizada quanto a reuso de águas residuais.

\section{AGRADECIMENTOS}

Os autores agradecem ao Instituto Federal de Educação, Ciência e Tecnologia do Rio Grande do Norte - IFRN, e ao Programa de Pós-Graduação de Mestrado Profissional em Uso Sustentável de Recursos Naturais.

\section{REFERÊNCIAS}

BACKES, C; SANTOS, A.J.M; GODOY, L.J.G; BÔAS, R.L.V; OLIVEIRA, M.R; OLIVEIRA. F.C. Doses de lodo de esgoto compostado em produção de tapete de grama esmeralda imperial. Revista Brasileira Ciências Solo v.37, p. 1402-1414. 2013 
BERTONCINI, E.I. Tratamento de Efluentes e Reúso da Água No Meio Agrícola. Revista Tecnologia \& Inovação Agropecuária. 2008.

CALDEIRA, M.V.W., DELARMELINA, W.M., FARIA, J.C.T., JUVANHOL, R.S. Substratos alternativos na produção de mudas de Chamaecrista desvauxii. Revista Árvore, v.37, p. 31-39, 2013.

CAMARGO, R; MALDONADO, A.C.D; SILVA, COSTA, T.R. Biossólido como substrato na produção de mudas de pinhão-manso. Revista Brasileira de Engenharia Agrícola e Ambiental v.14, p.1304-1310. 2010.

FILHO, M.B; CRISTINA, T. Viabilização do semiarido do nordeste: um enfoque multidisciplinary/ organizadores. 2010.

FRIEDLER, E. Water reuse an integral part of water resources management: Israel as a case study. 2000.

HESPANHOL, I. Água e saneamento básico - Uma visão realista. In: REBOUÇAS, A. C.; BRAGA, B.; TUNDISI, J.G. (Orgs). Águas Doces no Brasil - Capital Ecológico, Uso e Conservação. 2. ed. São Paulo: Escrituras, 2002.

IBGE, Censo Demográfico 2010. http://www.ibge.gov.br/. Acessado em: 31 ago. 2015.

JUNIO, G.R.Z; SAMPAIO, R.A; SANTOS, G.B; NASCIMENTO, A.L; PRATES, F.B.S; FERNANDES, L.A. Metais pesados em milho fertilizado com fosfato natural e composto de lodo de esgoto. Revista Brasileira de Engenharia Agrícola e Ambiental v.15, p.1082-1088, 2011.

MARQUES, M. O. et al. Uso de esgotos tratados em irrigação: Aspectos agronômicos e ambientais. In: BASTOS, R. K. X. (coord.). Utilização de esgotos tratados em fertirrigação, hidroponia e piscicultura. Rio de Janeiro: ABES, RIMA, p. 61-116. 2003.

MOTA, F.S.B; SPERLING, M.V. Nutrientes de Esgoto Sanitários: Utilização e Remoção. ABES, Rio de Janeiro, 2009.

Mundo Educação. http://www.mundoeducacao.com/quimica/. Acessado em: 31 ago. 2015.

NASCIMENTO, A.L; SAMPAIO. R.A; CRUZ. S.F; JUNIO. G.R.Z; BARBOSA, C.F; FERNANDES. L.A. Metais pesados em girassol adubado com lodo de esgoto submetido a diferentes processos de estabilização. Revista Brasileira de Engenharia Agrícola e Ambiental v.18, p.694-699. 2014.

NÓBREGA, R.S.A; BOAS, R.C.V; NÓBREGA, J.C.A; PAULA, A.M; MOREIRA, F.M.S. Utilização de biossólido no crescimento inicial de mudas de aroeira (Schinus terebynthifolius Raddi). Revista Árvore v.31, p.239-246. 2007 
OLIVEIRA, C; SOBRINHO, C.N.M.B.A; MAZUR, N. Solubilidade de metais pesados em solos tratados com lodo de esgoto enriquecido. Revista Brasileira Ciência Solo v.27 p. 171-181. 2003.

PESCOD, M.B. Wastewater treatment and use in agriculture. Roma: FAO. 1992.

SHUVAL, H. I.; ADIN, A.; FATTAL, B.; RAWITZ, E.; YEKUTIEL, P. Wastewater irrigation in developing countries: health effects and technical solutions. Word Bank Technical Paper, Washington, DC: The Work Bank, n. 51. 1986.

SHUVAL, H. Wastewater recycling and reuse as a water resource for Mediterranean countries hygienic and technological aspects. In: La collecte, le traitement et la reutilization des eaux usées: Aspects sanitaires de la réutilisation des eaux usées. II Conférece Méditerranéenne sur l’Eau. Rome, 1992. Disponível em:

http://www.oieau.fr/rome/france/expert/theme_3/. Acesso em: 01 set. 2015.

SNIS, 2013. http://www.snis.gov.br/. Acessado em: 31 ago. 2015.

WHO - WORLD HEALTH ORGANIZATION. Guidelines for the safe use of wastewater, excreta and greywater. Wastewaer Use in Agriculture. p.218. 2006. 